\title{
EXTRAÇÃo AQUOSA ENZIMÁTICA DE ÓLEO DE SOJA ${ }^{1}$
}

\author{
Renata Dinnies SANTOS ${ }^{2}$, Roseli Aparecida FERRARI ${ }^{2, *}$
}

\section{RESUMO}

O tratamento enzimático em meio aquoso tem se mostrado eficiente na degradação das paredes dos tecidos vegetais, propiciando maior rendimento na extração do óleo, melhorias na qualidade nutricional do farelo e aumento na estabilidade do produto final. Este trabalho avaliou a atuação de enzimas comerciais (Alcalase - protease - e Celluclast - celulase) no processo de extração aquosa de óleo de soja, bem como a influência da concentração das enzimas, do tempo de extração e da diluição da amostra (soja) no rendimento final. Foram realizados quatro experimentos de extração e os resultados foram obtidos a partir de um planejamento fatorial $2^{3}$. A análise estatística mostrou que a variável mais significativa de todo processo de extração foi a diluição da amostra (1:20). O rendimento do processo de extração aquosa foi inferior ao processo de extração por solvente. O aumento na concentração enzimática e no tempo de extração favoreceu o rendimento. Das enzimas utilizadas, a Alcalase apresentou melhor eficiência na extração, sendo que a utilização das duas enzimas simultaneamente propiciou incremento significativo sobre o rendimento do processo.

Palavras-chave: protease; celulase; diluição; rendimento.

\section{SUMMARY}

AQUEOUS ENZYMATIC EXTRACTION OF SOYBEAN OIL. The aqueous enzymatic treatment has showed efficient in the degradation of the vegetable cell walls, propitiating bigger yield in the oil extraction, improvements in the bran nutricional quality and increase in the product stability. This work evaluated the commercial enzyme performance (Alcalase - protease - and Celluclast - cellulase) in the aqueous process of soybean oil extration, as well as the influence of the enzymes concentration, the extraction time and the dilution of the sample (soybean) in the final yield. Four experiments of extration were carried through and the results had been gotten from an factorial planning $2^{3}$. The statistics analysis showed that the most significant variable of all extration process was the sample dilution $(1: 20)$. The yield income of the process of aqueous extration was inferior to the process of solvent extraction. The increase in the enzymatic concentration and in the extraction time favored the yield. Of used enzymes, the Alcalase presented better efficiency in the extration, being that the use of two enzymes simultaneously propitiated significant increment on the process yield.

Keywords: protease; cellulase; dilution; yield.

\section{1 - INTRODUÇÃO}

A industrialização da soja no Brasil, coincidindo com a expansão da produção, iniciou-se na década de 50, nas pequenas empresas que se dedicavam ao esmagamento de outras oleaginosas, nos Estados da região Sul e em São Paulo [11]. Desde os anos 60, a quantidade produzida vem crescendo tão aceleradamente que, nos últimos anos, o país ocupa a segunda posição como produtor mundial dessa oleaginosa [15].

Os processos industriais normais utilizados na produção de óleo consistem de prensagem contínua ou hidráulica e/ou extração por solventes. Esses processos têm certos inconvenientes: equipamentos muito caros para instalar e manter, alto nivel de perigo devido às grandes quantidades de solvente empregadas e indesejáveis efeitos colaterais na qualidade dos produtos acabados, principalmente devido às altas temperaturas alcançadas em algumas etapas [20].

O Brasil ocupa uma posição privilegiada tanto em termos de biodiversidade quanto em capacidade de ge-

\footnotetext{
1. Recebido para publicação em 17/11/2003. Aceito para publicação em 21/12/2004 (001251).

2. Departamento de Engenharia de Alimentos. Universidade Estadual de Ponta Grossa. Endereço: Av. Gal. Carlos Cavalcanti, 4748 - Uvaranas. CEP: 84030-900 - PR - Brasil. E-mail: renatadinnies@uol.com.br; ferrarir@uepg.br

* A quem a correspondência deve ser enviada.
}

rar recursos renováveis em grande escala. Em relação à tecnologia enzimática, existe abundância de matéria-prima a ser utilizada em processos fermentativos e extrativos e enorme quantidade de biomassa a ser transformada por via enzimática em produtos diversificados e de maior valor agregado. O uso e produção de enzimas, em diferentes áreas da agroindústria de alimentos, mostram perspectivas futuras promissoras devido às várias características inerentes à ação das enzimas, que são compostos naturais, biodegradáveis e capazes de desempenhar reações específicas sem produzirem produtos secundários [4].

A extração enzimática de óleos vegetais, principalmente para aumentar o rendimento de obtenção de óleo, fornece resultados promissores quando aplicada simultaneamente com processos puramente mecânicos [8]. Trabalhos de utilização de enzimas no processamento de oleaginosas têm sido publicados [9, 17]. A partir das observações feitas sobre a acumulação do óleo nos espaços intracelulares em células vegetais, os pesquisadores têm estudado substâncias capazes de afetar a estrutura das células com objetivo de melhorar a extração de óleo, mas a aplicação de um tratamento enzimático requer uma estratégia específica para cada caso [19].

A hidrólise enzimática de sementes de soja para obtenção de óleo é um processo que consome pouca energia, reduz a aplicação de solventes orgânicos e fornece óleo de maior qualidade associado a proteína da torta de qualidade superior, mais segura para o consu- 
mo humano [7]. Para se realizar a extração do óleo, que se encontra nos vacúolos intracelulares, há necessidade de se romper paredes e membranas celulares. Os tratamentos mecânico e térmico causam a ruptura das estruturas celulares, porém, não são suficientes, já que parte do óleo permanece na célula, sem ser extraído [18]. Através da hidrólise, rompe-se a parede celular e há maior liberação de óleo, ocorrendo também o rompimento do complexo molecular lipoproteína e lipopolissacarídeo em moléculas simples, liberando óleo extra que por outro método não seria extraído [17].

A substituição parcial do solvente por enzimas, na extração de óleos vegetais, forma a base de uma patente publicada por FULLBROOK (UK Patent Application GB 2127425 A, n 8227661, 1984). FULLBROOK [7] observou, durante a hidrólise enzimática da soja moída, que parte do óleo poderia ser recuperado no processo. O rendimento da extração era inferior a 50\% quando a incubação era realizada em meio aquoso. Constatou ainda que o óleo ligado à proteína da soja formava uma emulsão estável, que podia ser rompida quando se adicionava solvente orgânico (hexana) durante a etapa de incubação enzimática. Nestas condições, 90\% do óleo era recuperado após a separação das fases.

A seleção das enzimas requer o conhecimento da composição do tecido vegetal da oleaginosa a ser processada. Tendo em vista que a parede celular é composta de diferentes polissacarídeos ligados a uma proteína estrutural, o extrato enzimático deve conter enzimas com diferentes atividades (celulases, hemicelulases, pectinases, amilases e proteases) [6].

A seleção dos extratos enzimáticos é o primeiro passo no desenvolvimento da técnica e depende da composição da parede celular da oleaginosa em questão. Quando se aumenta a concentração de enzima aumenta-se a recuperação do óleo, porém compromete-se a viabilidade econômica do processo, uma vez que o custo da enzima ainda é um fator limitante desta tecnologia [10]. O pré-tratamento da amostra antes da incubação enzimática pode definir a viabilidade desta técnica. Esta etapa é diferenciada e depende da matéria-prima usada no processamento [5,10].

Enzimas celuloliticas e hemiceluloliticas são as mais indicadas para degradar a parede celular. As pectinases também são efetivas, já que as substâncias pécticas são componentes estruturais de células vegetais. Misturas de enzimas e complexos com atividade múltipla são mais eficientes que as enzimas isoladas [18]. Além da escolha mais adequada do tipo de enzima a ser utilizada, devem-se considerar alguns parâmetros como $\mathrm{pH}$, temperatura, tamanho da partícula e agitação, pois as condições utilizadas no processo influenciam o rendimento da extração. Porém, um exame detalhado da correlação desses parâmetros com as enzimas ainda não está completamente esclarecido [16].

A desvantagem da extração enzimática aquosa de sementes oleaginosas (soja) está associada à quantidade de enzimas usadas durante e hidrólise, superior a $1 \%$ em relação ao peso da matéria-prima, o que, devi- do ao alto custo das enzimas comerciais limita o uso desta tecnologia [6].

Este trabalho teve como objetivos a avaliação dos efeitos do tempo de extração, concentração, tipo de enzima e diluição da amostra (soja) sobre o rendimento do processo de extração enzimática de óleo de soja. Além disso, foi avaliado o efeito combinado de protease e celulase agindo simultaneamente na mesma amostra.

\section{2 - MATERIAL E MÉTODOS}

A matéria-prima utilizada (soja), após processo de moagem, laminação e expansão, foi fornecida pela Empresa Coinbra, Ponta Grossa - PR. Amostras de enzimas celuloliticas (Celluclast) e proteolíticas (Alcalase) foram fornecidas pela empresa Novo Nordisk.

\section{1 - Caracteristicas da enzima Celluclast 1,5 L FG}

Celluclast 1,5L é um preparado líquido de celulose produzido por fermentação submersa de cepas selecionadas do fungo Trichoderma reeseri. A enzima catalisa a degradação de celulose em glicose, celobiose e polímeros com alto teor de glicose, sendo que o produto cumpre as especificações recomendadas pela FAO/OMS, JECFA, relativas a enzimas para uso alimentício. Essa enzima apresenta-se como um liquido marrom com densidade de aproximadamente $1,2 \mathrm{~g} / \mathrm{mL}$. Para aplicações práticas, as condições ótimas de temperatura estão entre 50 e $60^{\circ} \mathrm{C}$ e $\mathrm{pH}$ entre 4,5 e 6,0 [14].

\section{2 - Caracteristicas da enzima Alcalase 2,4L}

Alcalase é uma enzima proteolítica produzida por fermentação submersa de uma espécie selecionada de Bacillus licheniformis. O principal componente da enzima, Substilisin A (= Substilisin Carlsberg), é uma endoproteinase extensivamente descrita na literatura. A atividade da Alcalase é padronizada em Unidades Anson por grama (AU/g), sendo de 2,4UA/g. Esta enzima, assim como a Celluclast $1,5 \mathrm{~L}$, cumpre as especificações recomendadas pela FAO/OMS, JECFA, relativas a enzimas para uso alimentício. A temperatura ótima para ação da Alcalase é ao redor de $60^{\circ} \mathrm{C}$, e com $\mathrm{pH}$ entre 6,5 e 8,5 [13].

\section{3 - Determinação do teor de óleo na amostra}

A determinação do teor total de óleo na amostra (soja) foi realizada pelo método convencional de extração por solvente, seguindo metodologia oficial AOCS [1]. A análise foi realizada em triplicata.

\section{4 - Primeiro experimento de extração}

Inicialmente, após trituração, padronizou-se a granulometria da matéria-prima (soja) como menor que 14 mesh. As enzimas Alcalase 2,4L e Celluclast 1,5L foram diluídas em água a 0,5 e 1,0\% em relação ao peso da matéria-prima. Essas soluções foram adicionadas à amostra (soja) separadamente, resultando em proporção de 1:5 (soja:solução aquosa enzimática). A mistura foi mantida a $55^{\circ} \mathrm{C}$ e $150 \mathrm{rpm}$ em Incubadora Refrigera- 
da com Agitação TE - 422 Tecnal, por 2 e 4 horas, mantendo-se o pH natural da emulsão $(6,5)$. Em seguida, adicionou-se éter de petróleo e a amostra foi agitada para facilitar a remoção do óleo; a suspensão foi centrifugada. A fração etérea foi removida, e após evaporação do solvente, o óleo foi pesado para determinação do rendimento do processo.

Os resultados deste ensaio foram obtidos a partir de um planejamento fatorial $2^{3}$, utilizando-se o Software Statistic 5.0, tendo como principais variáveis o tempo de extração (2 e 4 horas), concentração da enzima (0,5 e 1,0\%) e tipo da enzima (Alcalase e Celluclast) [12].

\section{5 - Segundo experimento de extração}

O procedimento experimental realizado foi semelhante ao primeiro. Foram mantidas as mesmas concentrações, tempos, temperatura e pH. Neste experimento, as enzimas foram utilizadas simuntaneamente na mesma amostra de soja, nas concentrações de 0,5 e $1,0 \%$, resultando na proporção de 1:5 (soja:solução aquosa enzimática). As demais etapas foram idênticas às descritas no experimento anterior.

\section{6 - Terceiro experimento de extração}

Neste experimento, após a padronização da granulometria (menor que 14 mesh), foi realizado um tratamento térmico em estufa a $105^{\circ} \mathrm{C}$ por 30 minutos, visando provável inativação das enzimas presentes naturalmente na soja. A amostra (soja) foi diluída em água na proporção de 1:5 e 1:10. O substrato foi incubado (C24 Incubator Shaker) com enzima celulolitica (Celluclast), na concentração de 1,5 e 3,0\% no pH natural da emulsão $(6,5)$. A mistura foi mantida a $60^{\circ} \mathrm{C}$ e 150 rpm por 1,5 e 3 horas. Em seguida, o $\mathrm{pH}$ foi ajustado para 7,0 com adição de solução de $\mathrm{NaOH} 0,25 \mathrm{~N}$ e acrescentou-se a protease (Alcalase) na mesma concentração e mesmo tempo. Após o período de hidrólise (tempo total de 3 e 6 horas), a mistura foi centrifugada com éter de petróleo; a fração etérea foi removida, e após evaporação do solvente, o óleo foi pesado para determinação do rendimento do processo.

Os resultados deste ensaio foram obtidos a partir de um planejamento fatorial $2^{3}$, utilizando-se o Software Statistic 5.0, tendo como principais variáveis o tempo de extração (3 e 6 horas), concentração da enzima (1,5 e 3,0\%) e diluição da amostra (1:5 e 1:10) [12].

\section{7 - Quarto experimento de extração}

Este experimento foi semelhante ao anterior. As variáveis analisadas foram: diluição da amostra (1:5 e $1: 20$ ), tempo total de extração (3 e 12 horas) e concentração da enzima (1,5 e 6,0\%). Os resultados deste ensaio foram obtidos a partir de um planejamento fatorial $2^{3}$, utilizando-se o Software Statistic 5.0 [12].

\section{3 - RESULTADOS E DISCUSSÃO}

Através do método convencional de extração por solvente, determinou-se o teor de óleo na amostra de soja utilizada, sendo de $21,72 \%$. O conteúdo de óleo na soja normalmente é de 18 a 20\% [10], portanto, a amostra apresentou valor ligeiramente superior ao normal.

\section{1 - Primeiro experimento de extração}

Neste experimento foram avaliados os efeitos do tempo de extração, concentração e tipo de enzima sobre o rendimento do processo de extração enzimática de óleo de soja (Tabela 1).

TABELA 1. Planejamento experimental $\left(2^{3}\right)$ e rendimento do processo de extração enzimática de óleo de soja no primeiro experimento.

\begin{tabular}{ccccc}
\hline & Enzima & Concentração & Tempo & Rendimento (\%) \\
\hline 1 & - & - & - & 36,42 \\
2 & + & - & - & 10,27 \\
3 & - & + & - & 36,68 \\
4 & + & + & - & 12,65 \\
5 & - & - & + & 41,08 \\
6 & + & - & + & 11,60 \\
7 & - & + & + & 44,60 \\
8 & + & + & + & 13,01 \\
\hline
\end{tabular}

onde:

\begin{tabular}{lcc} 
& - & + \\
\hline Enzima & Alcalase & Celluclast \\
\hline Concentração & $0,5 \%$ & $1,0 \%$ \\
\hline Tempo & $2 \mathrm{~h}$ & $4 \mathrm{~h}$ \\
\hline
\end{tabular}

A análise dos efeitos mostrou que o tipo de enzima foi a variável mais significativa do processo de extração, seguida pelo tempo de extração. Os efeitos combinados de tempo e tipo de enzima sobre o rendimento são mostrados na Figura 1.
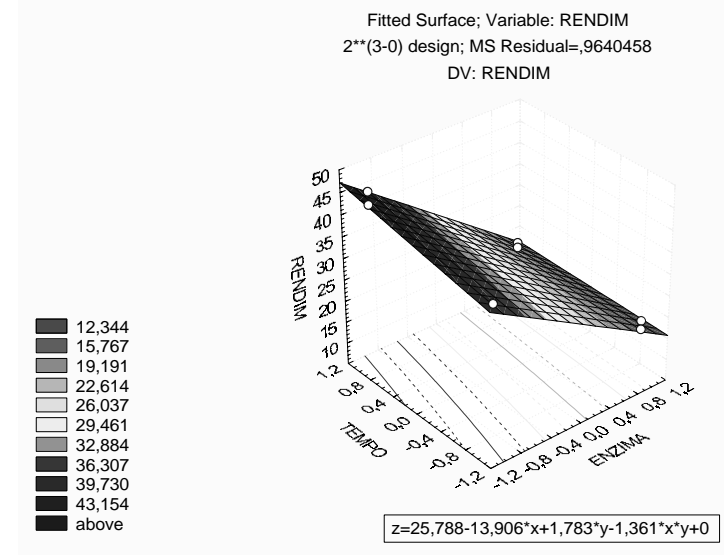

FIGURA 1. Influência do tipo de enzima (alcalase e celluclast) e do tempo de extração sobre o rendimento do processo no primeiro experimento, e respectiva equação matemática, onde $\mathrm{x}=$ tipo de enzima, $\mathrm{y}=$ tempo de extração $\mathrm{e}$ $\mathrm{x} . \mathrm{y}=$ interação entre tipo de enzima e tempo de extração. 
Ao comparar a atividade das duas enzimas utilizadas, observa-se que a enzima alcalase (-) foi mais eficiente na extração do óleo de soja que a celluclast $(+)$, sob mesmas condições experimentais. Considerando que proteínas são os principais constituintes da soja, em média $39,3 \%$, não é surpresa que os efeitos de proteases sejam geralmente melhores que os efeitos de outras enzimas, como celulases [3]. O forte efeito da protease comparado com outras enzimas pode ser atribuído também à produção de peptídios e aminoácidos pela hidrólise das proteínas, que apresentam alta solubilidade [16]. Porém, a utilização de um complexo multi-enzimático em substituição a uma única enzima pode fornecer melhores resultados, já que as paredes celulares não são uniformes; sua composição, forma e tamanho, dependem da função da célula dentro da planta. A chave da atividade enzimática necessária para abrir as paredes celulares de forma a liberar o óleo para uma fase oleosa baseia-se na degradação desses componentes [3, 20].

Mantendo-se a concentração da enzima constante e aumentando-se o tempo de extração de $2(-)$ para $4(+)$ horas, observa-se aumento no rendimento médio da extração. Para a enzima alcalase, o aumento no rendimento ficou em torno de 4,7\%, para concentração de 0,5\%, e 7,9\% para concentração de 1,0\%.

O aumento na concentração da enzima de 0,5 (-) para $1,0 \%(+)$ favoreceu como esperado o rendimento do processo de extração de óleo, tanto para alcalase quanto para celluclast (Figura 2), já que, de acordo com a literatura, a quantidade de enzimas usadas durante a hidrólise deve ser superior a $1 \%$ em relação ao peso da matéria-prima [6].

$$
\begin{gathered}
\text { Fitted Surface; Variable: RENDIM } \\
2 *(3-0) \text { design; } \text { MS Residual }=5,905379 \\
\text { DV: } \text { RENDIM }
\end{gathered}
$$

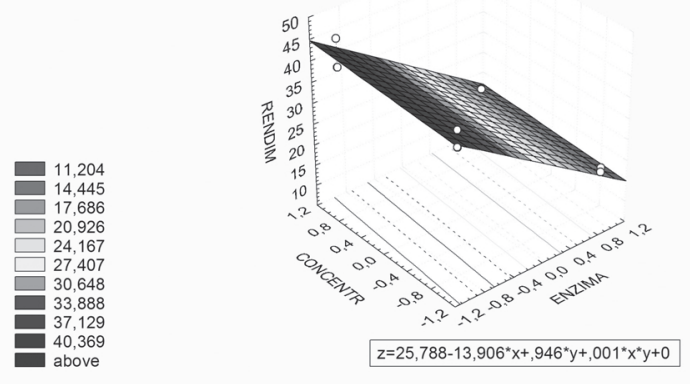

FIGURA 2. Influência do tipo e concentração de enzima (alcalase e celluclast) sobre o rendimento do processo no primeiro experimento e respectiva equação matemática, onde $\mathrm{x}=$ tipo de enzima, $\mathrm{y}=$ concentração da enzima e $\mathrm{x} . \mathrm{y}=$ interação entre tipo e concentração de enzima.

De acordo com a análise estatística realizada, a interação entre tempo e tipo de enzima (Figura 1) é mais significativa sobre o rendimento da extração do que as interações entre tipo de enzima e concentração (Figura 2) e tempo e concentração (Figura 3). Entretanto, é es- perado que aumento no tempo de extração e na concentração da enzima produzam melhores rendimentos na extração de óleo de soja.

$$
\begin{gathered}
\text { Fitted Surface; Variable: RENDIM } \\
2^{\star \star}(3-0) \text { design; } \text { MS Residual }=5,686879 \\
\text { DV: } \text { RENDIM }
\end{gathered}
$$

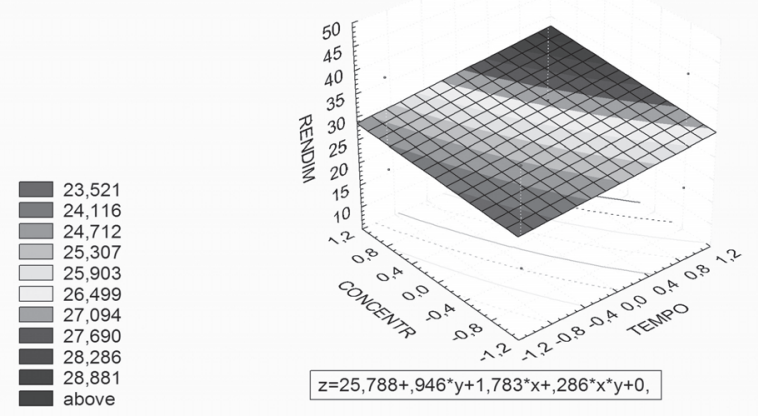

FIGURA 3. Influência do tempo de extração e da concentração de enzima sobre o rendimento do processo no primeiro experimento e respectiva equação matemática, onde $\mathrm{x}=$ tempo de extração, $\mathrm{y}=$ concentração da enzima e $\mathrm{x} . \mathrm{y}$ = interação entre tempo e concentração de enzima.

A combinação mais efetiva das variáveis foi: $1 \%$ de enzima (alcalase) durante 4 horas de extração, a qual forneceu o rendimento máximo de $44,6 \%$.

\section{2 - Segundo experimento de extração}

Neste ensaio foram utilizadas as duas enzimas simultaneamente na mesma amostra, com a finalidade de comparar o efeito combinado (+) com a ação isolada da protease - alcalase (-). Além desse efeito, foram avaliados também a influência do tempo de extração e a concentração da enzima sobre o rendimento do processo. O planejamento experimental e os resultados obtidos são mostrados na Tabela 2.

TABELA 2. Planejamento experimental $\left(2^{3}\right)$ e rendimento do processo de extração enzimática de óleo de soja no segundo experimento.

\begin{tabular}{ccccc}
\hline & Enzima & Concentração & Tempo & Rendimento $(\%)^{*}$ \\
\hline 1 & - & - & - & 36,42 \\
2 & + & - & - & 35,89 \\
3 & - & + & - & 36,68 \\
4 & + & + & - & 37,61 \\
5 & - & - & + & 41,08 \\
6 & + & - & + & 38,35 \\
7 & - & + & + & 44,60 \\
8 & + & + & + & 40,92 \\
\hline
\end{tabular}

onde:

\begin{tabular}{lcc}
\cline { 2 - 3 } & - & + \\
\hline Enzima & Alcalase & Alcalase + Celluclast \\
\hline Concentração & $0,5 \%$ & $1,0 \%$ \\
\hline Tempo & $2 \mathrm{~h}$ & $4 \mathrm{~h}$ \\
\hline
\end{tabular}

* Rendimento calculado com base na extração por solvente em Soxhlet. 
Através da análise estatística e dos modelos matemáticos gerados (Equações 1, 2 e 3), percebe-se que a mistura das duas enzimas (alcalase e celluclast) não teve efeito significativo sobre o rendimento. As duas enzimas foram incubadas ao mesmo tempo e sob mesmas condições de $\mathrm{pH}$ e temperatura. Porém, sabe-se que cada enzima apresenta um pH ótimo de atuação, bem como uma temperatura ótima, e essas condições não foram observadas nesse experimento. Isso pode ter sido a causa do baixo rendimento, juntamente com as duas enzimas atuando ao mesmo tempo. Sabe-se que uma enzima pode interferir na ação de outra. Portanto, o ideal seria deixar apenas uma enzima agir, inativá-la e somente depois adicionar a outra, observando sempre as condições ótimas de $\mathrm{pH}$ e temperatura.

Das três variáveis analisadas (tipo de enzima - somente alcalase e mistura de alcalase e celluclast, tempo de extração e concentração enzimática), apenas o tempo teve efeito significativo sobre o rendimento. As interações entre as variáveis também não foram significativas. A combinação das variáveis que forneceu o melhor rendimento $(44,60 \%)$ foi enzima Alcalase, a 1,0\% durante 4 horas de extração.

Modelos matemáticos:

$$
z=38,944-0,7512 * x+2,294 * y-0,851 * x * y+0
$$

onde $\mathrm{x}=$ tipo de enzima e $\mathrm{y}=$ tempo de extração.

$z=38,944-0,7512 * x+1,009 * y+0,064 * x * y+0$

onde $\mathrm{x}=$ tipo de enzima e $\mathrm{y}=$ concentração da enzima.

$z=38,944+1,009 * y+2,294 * x+0,514 * x * y+0$

onde $\mathrm{x}=$ tempo de extração $\mathrm{e} \mathrm{y}=$ concentração da enzima.

\section{3 - Terceiro experimento de extração}

Antes de iniciar o processo de extração, a soja foi submetida a tratamento térmico visando inativação das enzimas naturais que, porventura, poderiam estar presentes e influenciar a hidrólise enzimática.

Neste ensaio, foram avaliados os efeitos do tempo de extração, concentração da enzima e diluição da amostra. O planejamento experimental e os resultados obtidos são mostrados na Tabela 3.

Pela análise estatística dos dados obtidos, determinou-se que a diluição foi a variável mais significativa do processo de extração, seguida da concentração. Mantendo-se as mesmas condições de tempo de extração e concentração enzimática, e aumentando-se a diluição de 1:5 (-) para 1:10 (+), observa-se aumento médio de $12,5 \%$ no rendimento da extração. Isso pode ser devido a maior transferência de massa que ocorre entre a amostra e a solução, portanto, alta diluição em água promove maior desintegração da estrutura celular e dos complexos, auxiliando na mobilização e ação das enzimas hidrolíticas [2]. A Figura 4 mostra o efeito da diluição da amostra e do tempo de extração sobre o rendimento final. Esta interação foi a mais significativa de todo o processo. Pode-se perceber que quanto maior a diluição e o tempo de extração, maior o rendimento do processo.

TABELA 3. Planejamento experimental $\left(2^{3}\right)$ e rendimento do processo de extração enzimática de óleo de soja no terceiro experimento.

\begin{tabular}{ccccc}
\hline & Diluição & Tempo & Concentração & Rendimento $(\%)^{\star}$ \\
\hline 1 & - & - & - & 36,42 \\
2 & + & - & - & 35,89 \\
3 & - & + & - & 36,68 \\
4 & + & + & - & 37,61 \\
5 & - & - & + & 41,08 \\
6 & + & - & + & 38,35 \\
7 & - & + & + & 44,60 \\
8 & + & + & + & 40,92 \\
\hline
\end{tabular}

onde:

\begin{tabular}{lcc}
\cline { 2 - 3 } & - & + \\
\hline Diluição & $1: 5$ & $1: 10$ \\
\hline Tempo & $3 \mathrm{~h}$ & $6 \mathrm{~h}$ \\
\hline Concentração & $1,5 \%$ & $3,0 \%$ \\
\hline
\end{tabular}

* Rendimento calculado com base na extração por solvente em Soxhlet.

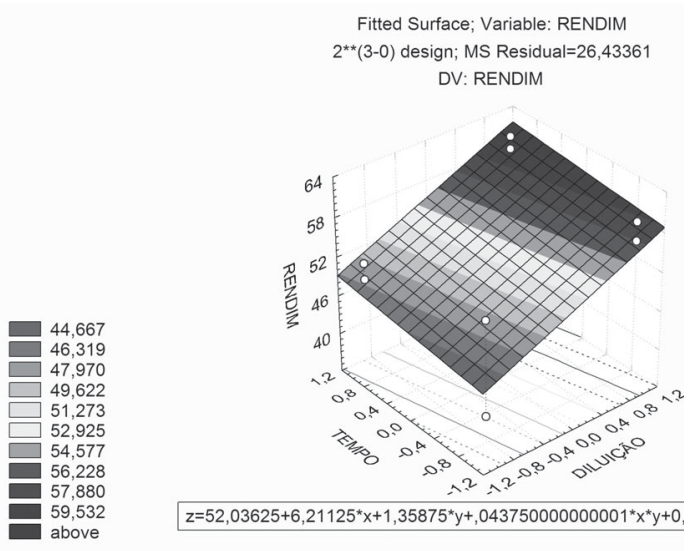

FIGURA 4. Efeito do tempo de extração e diluição da amostra sobre o rendimento do processo no terceiro experimento e respectiva equação matemática, onde $\mathrm{x}=$ diluição, $\mathrm{y}$ = tempo de extração e $\mathrm{x} . \mathrm{y}$ = interação entre diluição e tempo de extração.

A análise estatística das interações entre diluição e concentração e tempo e concentração tiveram a mesma significância sobre o rendimento do processo de extração. 
Ao comparar os resultados obtidos nos experimentos anteriores, onde foram utilizadas as enzimas isoladamente, com os resultados deste experimento, onde foram utilizadas as duas enzimas simultaneamente, verifica-se aumento no rendimento médio do processo de extração. De acordo com BARGALE [3], esse é um efeito esperado, já que a parede celular é composta de diferentes substâncias, dentre as quais, proteínas e polissacarídeos. Além do mais, as condições de $\mathrm{pH}$ e temperatura foram otimizadas para cada enzima, aumentando, assim, a eficiência da ação das mesmas.

Para este experimento, o maior rendimento obtido foi de $60,77 \%$, quando se utilizou diluição $1: 10$, durante 6 horas de extração, com concentração enzimática de $3 \%$. Vale a pena observar que se utilizando as mesmas condições de diluição e tempo e reduzindo a concentração enzimática para $1,5 \%$, o rendimento foi de $58,53 \%$. Isso comprova a grande influência da diluição sobre o rendimento da extração. Essa é uma variável que merece destaque, pois uma das limitações da extração enzimática é justamente a quantidade de enzima a ser utilizada, já que o custo da mesma é elevado, limitando o uso dessa tecnologia.

A Figura 5 relaciona todas as variáveis do processo, bem como as interações entre elas. Pode-se perceber a grande influência da diluição sobre o rendimento, confirmando mais uma vez o que foi discutido anteriormente. A segunda variável mais significativa foi a concentração enzimática.

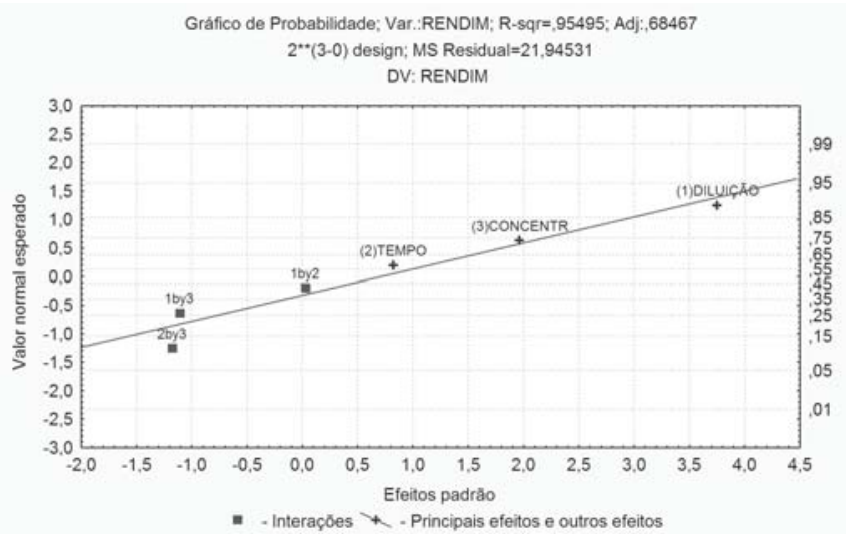

FIGURA 5. Gráfico de probabilidade, efeitos e interações no terceiro experimento.

\section{4 - Quarto experimento de extração}

Este ensaio foi semelhante à terceira extração; foram avaliados os efeitos do tempo de extração, concentração da enzima e diluição da amostra. O planejamento experimental e os resultados obtidos são mostrados na Tabela 4.

Através da análise estatística dos dados obtidos, foi possível confirmar novamente que a diluição da amostra é um fator relevante sobre o rendimento do processo, como pode ser observado na Tabela 4. A con- centração enzimática utilizada neste ensaio foi bastante elevada, portanto era esperado alto rendimento. Porém, apenas aumentando a diluição de 1:5 (-) para 1:20 (+) e mantendo-se as demais variáveis (tempo e concentração) constantes, observa-se aumento médio no rendimento de $16,77 \%$. As interações entre as variáveis, bem como o efeito de cada variável sobre o rendimento do processo são mostrados na Figura 6.

De acordo com a Figura 6, observa-se que o tempo foi a variável menos significativa. A interação entre diluição e concentração foi a mais significativa no processo de extração.

TABELA 4. Planejamento experimental $\left(2^{3}\right)$ e rendimento do processo de extração enzimática de óleo de soja no terceiro experimento.

\begin{tabular}{ccccc}
\hline & Diluição & Tempo & Concentração & Rendimento (\%)* \\
\hline 1 & - & - & - & 35,82 \\
2 & + & - & - & 55,01 \\
3 & - & + & - & 38,55 \\
4 & + & + & - & 51,70 \\
5 & - & - & + & 50,99 \\
6 & + & - & + & 67,33 \\
7 & - & + & + & 40,94 \\
8 & + & + & + & 59,34 \\
\hline
\end{tabular}

\begin{tabular}{lcc}
\hline \multirow{2}{*}{ onde: } & & \\
\cline { 2 - 3 } & - & + \\
\hline Diluição & $1: 5$ & $1: 20$ \\
\hline Tempo & $3 \mathrm{~h}$ & $12 \mathrm{~h}$ \\
\hline Concentração & $1,5 \%$ & $6,0 \%$ \\
\hline * Rendimento calculado com base na extração por solvente em Soxhlet.
\end{tabular}

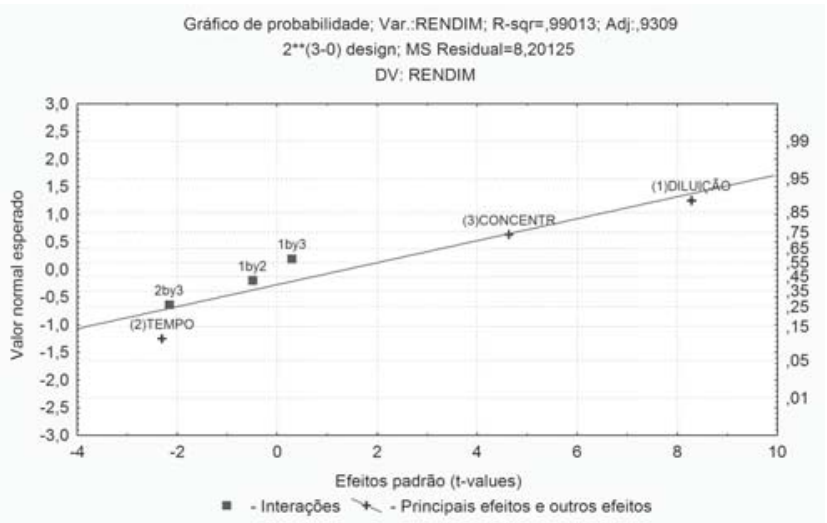

FIGURA 6. Gráfico de probabilidade, efeitos e interações no quarto experimento.

\section{4 - CONCLUSÕES}

O rendimento do processo de extração enzimática aquosa de óleo de soja foi inferior ao processo de extração por solvente. O aumento na concentração enzimática e no tempo de extração favoreceu o rendimento 
do processo. Aumentando-se a diluição da amostra, verificou-se aumento no rendimento médio da extração, visto que ocorreu maior interação entre a solução enzimática e a soja. Das enzimas utilizadas, a alcalase apresentou melhor eficiência na extração. A utilização das duas enzimas simultaneamente (alcalase e celluclast) favoreceu o rendimento da extração. A variável mais significativa de todo processo de extração foi a diluição da amostra (1:20).

\section{5 - REFERÊNCIAS BIBLIOGRÁFICAS}

[1] AOCS. Official methods and recommended practices of the American Oil Chemist's Society. 3 ed. Champaign, 1996.

[2] BADR, F.H.; SITOHY, M.Z. Optimizing conditions for enzymatic extraction of sunflower oil. Grasas y Aceites, v. 43, n. 5, p. 281-283, 1992.

[3] BARGALE, P.C. Enzymatic hidrolysis of soybean for solvent and mechanical oil extraction. Journal of Food Process Engineering, n. 23, p. 321-327, 1992.

[4] COURI, S. Tecnologia enzimática: preparações enzimáticas na produção de alimentos. Embrapa 10, 757 p., 1998.

[5] DOMINGUEZ; H.; NÚNEZ, M.J.; LEMA, J.M. Enzymatic pretreatment of enhance or extraction from fruits and oilseeds: a review. Food Chemistry, n. 49, p. 271-286, 1994.

[6] FREITAS, S.; HARTMAN, L.; COURI, S. Alternativa biotecnológica ao uso de solventes orgânicos na extração de óleos vegetais. Óleos e Grãos, n. 32, p. 29-32, 1996.

[7] FULLBROOK, P. D. The use of enzymes in the Processing Oilseeds. Journal of AOCS, v. 60, n. 2, p. 476-478, 1983.

[8] GOMES, C. Embrapa. Disponível em:<www.cnpso.embrapa. br/imprcon.htm $>$ Acesso em 12 set. 2002.

[9] HANMOUNGJAI, PYLE, D.L.; NIRAJAN, K. Enzymatic process for extracting oil and protein from rice bran. Journal of AOCS, v. 78, n. 8, p. 817-821, 2001.

[10] HARTMAN, L; FREITAS, S.P.; COURI, S.; CARVALHO, C.W.P.; JABLONKA, F.H. 1996. Processo de hidrólise enzimática da soja para obtenção do óleo e das proteínas modificadas; óleo de soja; proteínas modificadas. Patente de Invenção 1100048-1 A. Embrapa.
[11] MIYASAKA, S.; MEDINA, J. C. A soja no Brasil. Fundação Cargill, p. 752-927, 1981.

[12] NETO, B.B.; SCARMINIO, J.S.; BRUNS, R.E. Planejamento e otimização de experimentos. Campinas-SP, Editora da Unicamp, p. 61-187, 1995.

[13] NOVOZYMES. Alcalase food grade. Special Food 08281$01,2001$.

[14] NOVOZYMES. Celluclast 1,5L FG. Special Food 0852401, 2001.

[15] PARK, Y.K.; AGUIAR, C.L.; ALENCAR, S.M.; MASCARENHAS, H.A.A.; SCAMPARINI, A.R.P. Conversion of malonyl beta-glycoside isoflavones into glycoside isoflavones in brazilian soybeans. Ciênc. Tecnol. Aliment., v. 22, n. 2, p. 130-135, 2002.

[16] ROSENTHAL, A.; PYLE, D.L.; NIRANJAN, K.; GILMOUR, S.; TRINCA, L. Combined effect of operational variables and enzyme activity on aqueous enzymatic extraction of oil and protein from soybean. Enzyme and Microbial Technology. Elsevier Science Inc. v. 28, n. 6, p. 499-509, 2001.

[17] SHANKAR, D.; AGRAWAL, Y.C.; SARKAR, B.C.; SINEH, B.P.N. Enzymatic hydrolisys in conjunction with conventional pretreatments to soybean for enhanced oil availability and recovery. Journal of AOCS, v. 74, n. 12, p. 1543-1547, 1997.

[18] SINEIRO, J.; DOMÍNGUEZ, H.; NÚÑEZ, M.J. Influencia del tratamiento enzimático en la calidad de aceites vegetales. Grasas y Aceites, v. 49, n. 2, p. 191-202, 1998.

[19] SOSULSKI, F.W. The centrifuge method for determining flour absorption in hard red spring wheat. Cereal Chemistry, v. 39, p. 344-349, 1962.

[20] TURATTI, J.M. Extração de óleos vegetais utilizando-se enzimas no pré-tratamento das sementes. Campinas, 1999, 89p. Dissertação (Mestre em Ciência de Alimentos), Faculdade de Engenharia de Alimentos, Universidade Estadual de Campinas (UNICAMP).

\section{6 - AGRADECIMENTOS}

Ao CNPq e à Fundação Araucária pelo apoio concedido, e às empresas Coinbra SA e Novo Nordisk, pelo fornecimento de amostras para a realização do trabalho. 